\title{
CARSEY INSTITUTE
}

\section{The Increasing Diversity of America's Youth Children Lead the Way to a New Era}

\author{
Kenneth M. Johnson, Andrew Schaefer, Daniel T. Lichter, and Luke T. Rogers
}

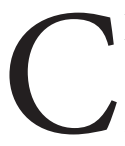
hildren are in the vanguard of America's increasing racial and ethnic diversity. The majority of newborn babies today are among racial and ethnic minority populations, according to recent Census Bureau estimates. U.S. Census Bureau projections indicate that by 2043 , non-Hispanic whites will cease to be a majority of the American population. For America's children and youth, the future is now. ${ }^{1}$ American diversity is fueled by differing fertility rates among racial and ethnic groups, changes in the racial composition of women of childbearing age, and immigration. Here we document how unfolding demographic forces have placed today's children and youth at the forefront of America's new racial and ethnic diversity. America's rapidly changing racial and ethnic composition has important implications for intergroup relations, ethnic identities, and electoral politics. ${ }^{2}$

Much of the growing racial diversity is caused by unprecedented population increases of minority children, particularly Hispanic children. It is also due to a significant numerical decline in the number of nonHispanic white children, which is less often appreciated. The Great Recession reduced fertility and domestic migration rates and slowed the flow of immigrants, yet the demographic forces fueling diversity are unrelenting. Diversity has unfolded unevenly in geographic space. More than 600 U.S. counties, or approximately one-fifth of U.S. counties, had "majority-minority" youth populations in 2012-a number considerably higher than for the U.S. population overall. The frequent claim that we live in an increasingly multiracial or multicultural society does not necessarily mean

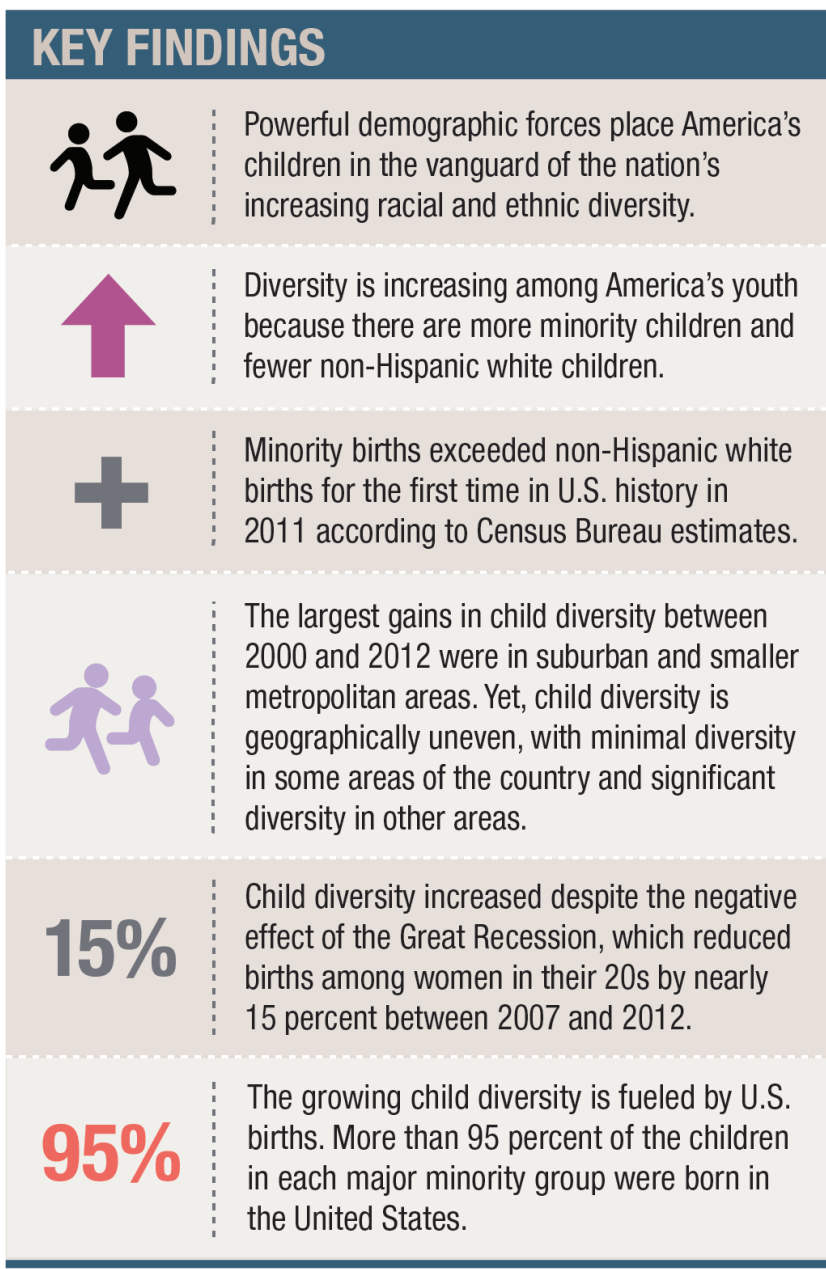

that national patterns have played out at the local or regional level. Racial diversity is spreading unevenly from state to state, community to community, and neighborhood to neighborhood. 


\section{Increasing Racial and Ethnic Diversity Among America's Children}

Approximately 37 percent of the U.S. population was a racial or ethnic minority in 2012. The pace of this change has been particularly rapid among America's children and youth. In 1990, 32 percent of the population younger than age 20 was minority, increasing to 39 percent in 2000. By July of 2012, 47 percent of the 82.5 million people under age 20 in America were from minority populations (Figure 1). In contrast, minorities represented only 33 percent of the 231.4 million residents age 20 or older. Within this older population, Hispanics (14 percent) constituted a slightly larger share of the population than blacks (12 percent). However, among those under age 20 , Hispanics constituted 24 percent and blacks constituted 14 percent.

The acceleration of racial and ethnic diversity is evidenced further when we compare preschool-age children with older teenagers. Minorities represented 48 percent of the population under age 5 in 2012 but only 43 percent among 15- to 19-year-olds. This age gradient of minority representation clearly highlights America's new and increasing diversity.

The growth of America's minority population, coupled with recent population declines of non-Hispanic white children, fuel the growing youth diversity in the United States. Between 2000 and 2012, the number of minority young people grew by 7.7 million (25 percent). The Hispanic youth population accounted for 5.8 million, or approximately 75 percent of the increase in the U.S. minority

\section{FIGURE 1. ADULT AND YOUTH POPULATION BY RACE/HISPANIC ORIGIN, 2012}

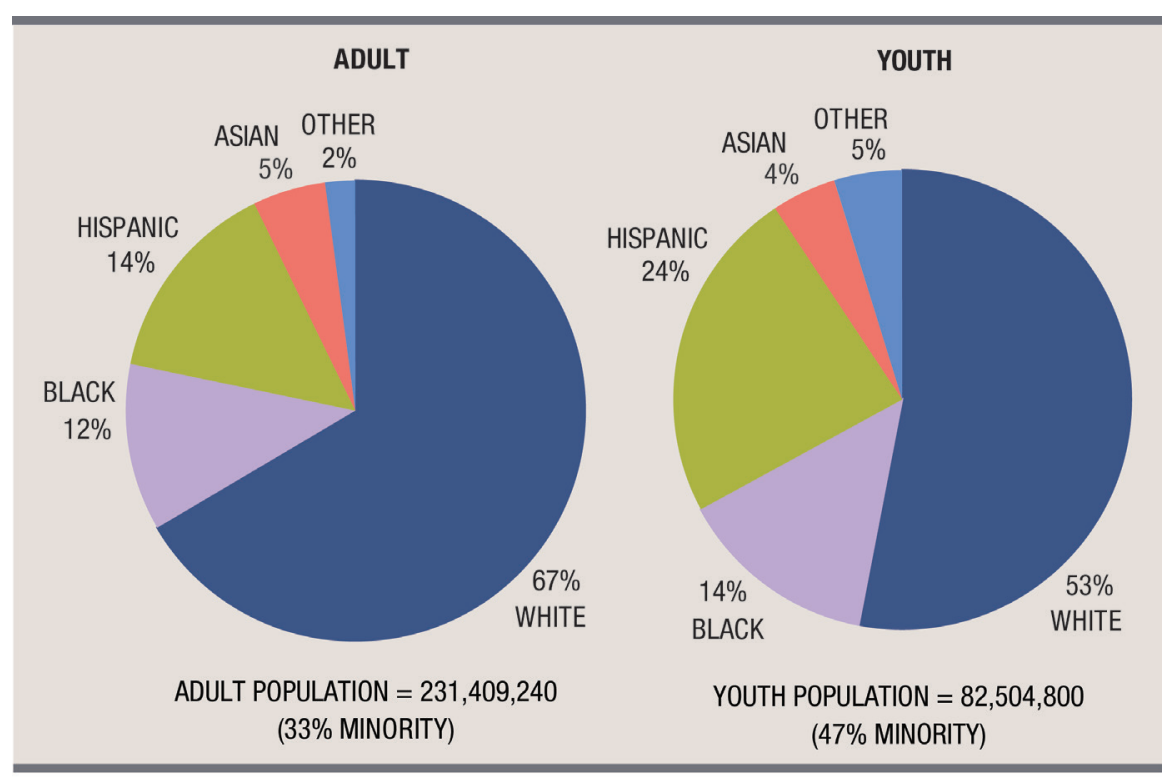

Source: U.S. Census Population Estimates (2012)

Notes: Adults are age 20 and over, and youth are under age 20. Hispanic category includes Hispanics of any race. Other category includes native peoples and those of two or more races.

population under age 20 , after increasing by 42 percent between 2000 and 2012 (Figure 2). This recent gain supplements substantial Hispanic population gains during the 1990s. The number of people under 20 in the "other" minority group (primarily Asian and multiracial) grew by 2.3 million (42 percent) between 2000 and 2012. In contrast, the young black population declined ( -2.8 percent) during the same period. The population decline of young blacks-historically the largest minority group in the country-underscores the fundamental demographic changes underway in America's minority population.

The rapid growth of the minority youth population contrasts sharply with patterns among young whites. The number of young whites increased by only 54,000 (1 percent) during the 1990s. However, since 2000, the number of young non-Hispanic whites has declined by 5.7 million (-11.5 percent). As a result, the proportion of young people who are non-Hispanic white declined from 61 to 53 percent between 2000 and 2012.

\section{Minority Births Increase, White Births Diminish}

Fertility has played an important role in the shifting patterns of racial diversity. In 1990, non-Hispanic whites accounted for nearly twothirds of all births. Blacks accounted for the second largest number of births (17 percent), followed by Hispanics (15 percent). By 2012, U.S. births decreased by 5 percent compared with 1990, but Hispanic births had risen by more than 50 percent. Births to non-Hispanic whites and blacks diminished during the same period. By 2012, non-Hispanic white births represented slightly less than half of all births according to Census Bureau estimates, while Hispanic births grew to 26 percent of all births. 
FIGURE 2. ANNUALIZED POPULATION CHANGE FOR THOSE UNDER AGE 20 BY RACE/HISPANIC ORIGIN, FROM 1990 TO 2000 AND FROM 2000 TO 2012

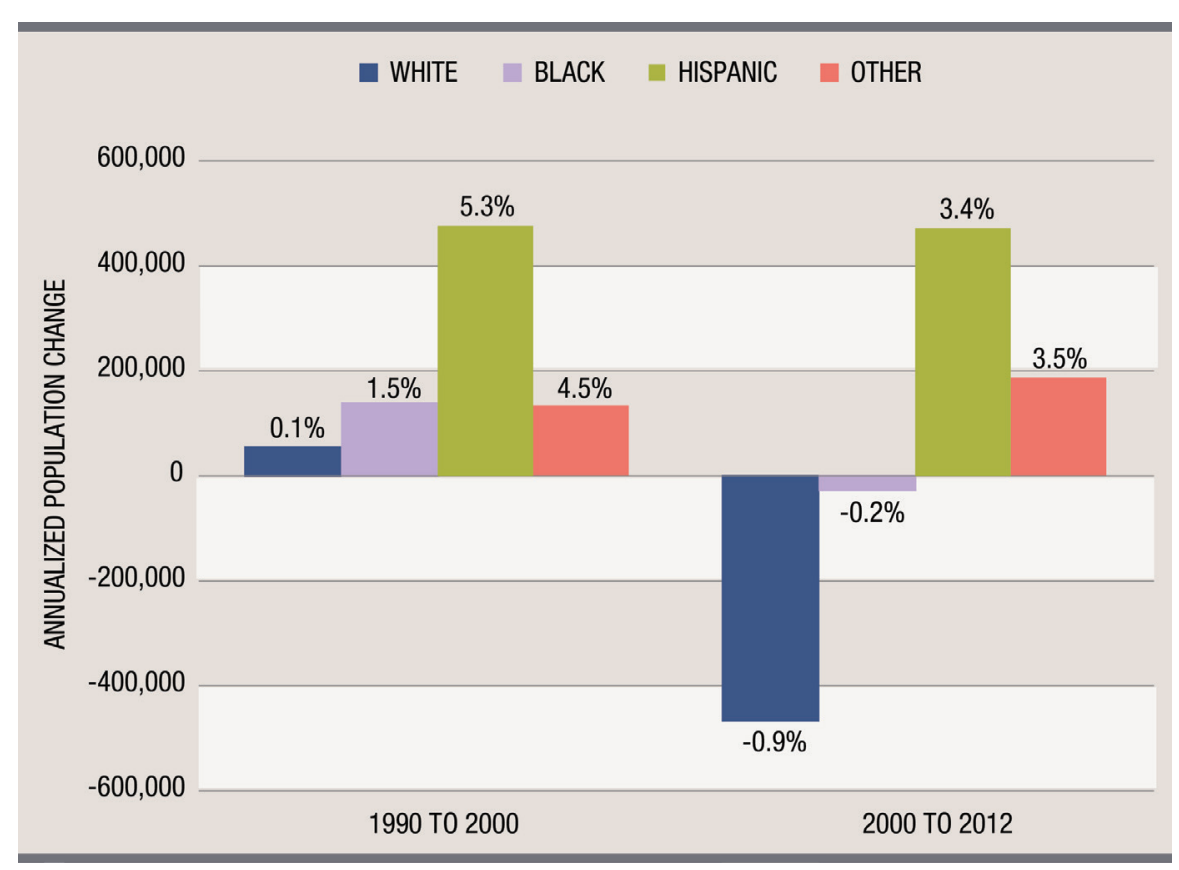

Source: Decennial Census 1990 and 2000; U.S. Census Population Estimates (2012)

African-America births remained stable at 15 percent of the total.

Differences with regard to race and Hispanic origin among women in their prime childbearing years (ages 20 to 39) contributed significantly to America's changing racial and ethnic mix. During the 1990s, the number of non-Hispanic white women of prime childbearing age declined by nearly 4 million $(-12.8$ percent) and declined by another 2.4 million between 2000 and 2012 (Figure 3). In contrast, the number of minority women of prime childbearing age grew by 2.8 million (25 percent) in the 1990s and by 3.8 million ( 25 percent) between 2000 and 2012. Hispanic women accounted for slightly more than 61 percent of this absolute minority gain. The number of other minority women in their prime childbearing years also increased significantly, although population gains among black women were minimal.

The cumulative effect of these changes in the number of women of prime childbearing age has been considerable. By 2012, there were 6.2 million (-21 percent) fewer nonHispanic white women of prime childbearing age than there were in 1990. In contrast, 6.6 million (58 percent) more minority women were in their prime childbearing years. As a result, the proportion of all women in their prime childbearing years who were non-Hispanic white decreased from 73 percent to 57 percent between 1990 and 2012 .

High Hispanic fertility rates, along with early childbearing, combined with increasing numbers of Hispanic women to produce large increases in births to Hispanic mothers in the past two decades. Hispanic women continue to have higher fertility rates than their counterparts, although their total fertility rate declined significantly from nearly 3 children in 1990 to roughly 2.2 children in 2012 (Figure 4). Early childbearing also characterizes the Hispanic population; 44 percent of all Hispanic newborns had mothers younger than age 25. In contrast, non-Hispanic white women delayed childbearing and had lower fertility rates; approximately 30 percent of white babies were born to mothers younger than age 25 .

Black women also have children at a younger age than the U.S. average, but declining black fertility has diminished the young black population. The groups that constitute most "other" minorities (Asians and multiracial groups) also had low total fertility rates, so population gains were primarily attributable to the rising numbers of women of childbearing age in this group rather than to high fertility rates. Clearly, below-replacement fertility among non-Hispanic whites intensifies the demographic effect

The Great Recession has had a significant impact on U.S. fertility. Overall, births dropped from 4.3 million in 2007 to slightly less than 4 million in 2012-a decline of 8.4 percent.

of increasing numbers of minority women with high fertility rates on America's racial and ethnic diversity.

The Great Recession has had a significant impact on U.S. fertility. Overall, births dropped from 4.3 million in 2007 to slightly less than 4 million in 2012-a decline of 8.4 percent. Furthermore, the latest data do not suggest a recovery in 
FIGURE 3. ANNUALIZED POPULATION CHANGE OF WOMEN AGED 20-39, FROM 1990 TO 2000 AND FROM 2000 TO 2012

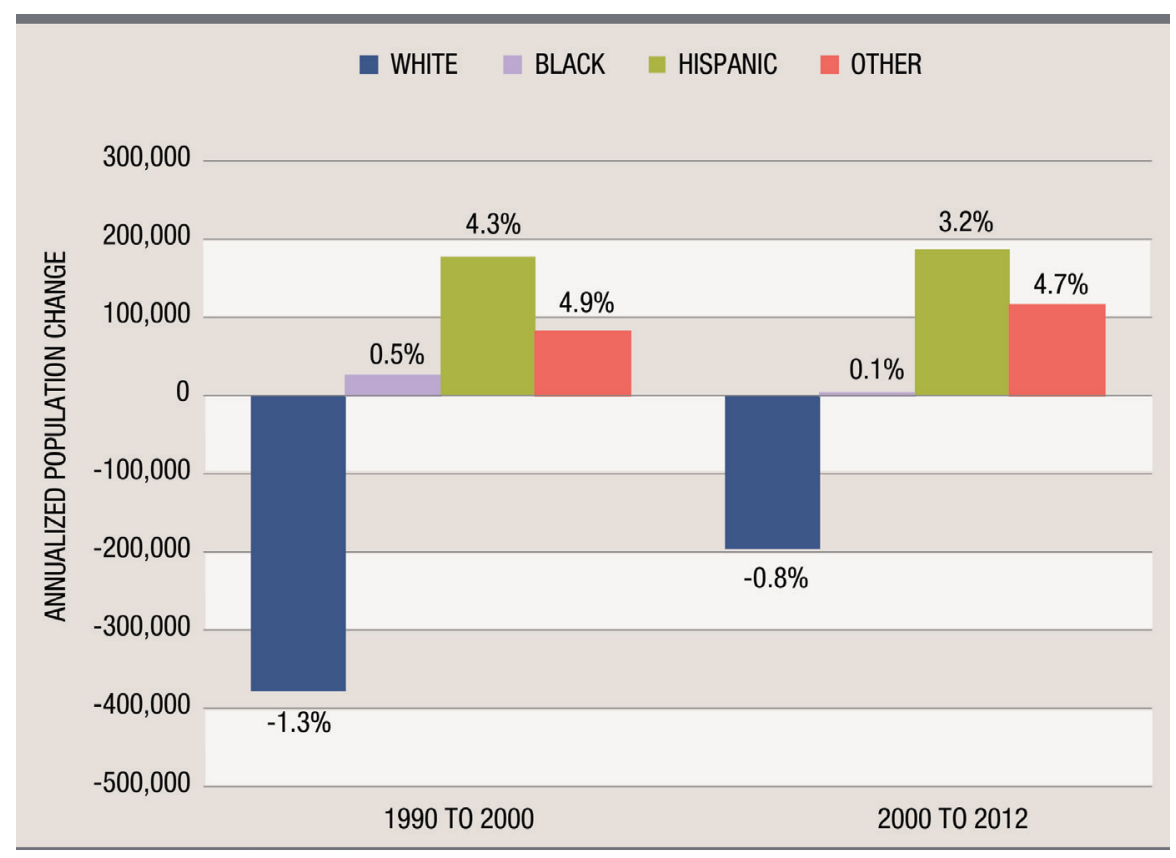

Source: Decennial Census 1990 and 2000; U.S. Census Population Estimates (2012)

FIGURE 4. TOTAL FERTILITY RATE BY RACE AND HISPANIC ORIGIN, 1990, 2000, 2007, AND 2012

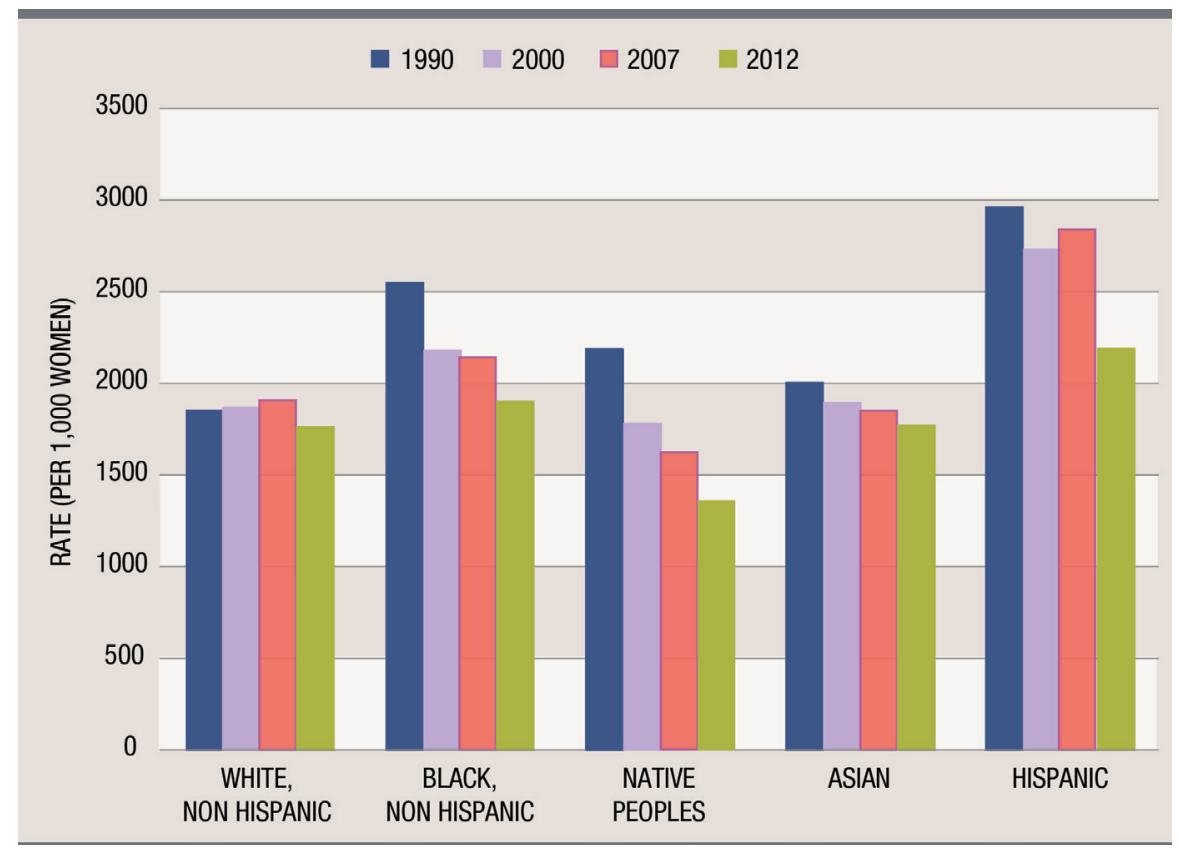

Source: NCHS 1990 to 2012 fertility rates. Fewer births have implications for the diversity of the child population because recessionary declines in fertility rates have been uneven among racial and ethnic populations. Fertility rate declines were much higher for women in their 20s than for women in their 30s. Between 2007 and 2012, the fertility rate of women in their 20s dropped by 15.3 percent compared with a gain of 0.8 percent for women in their 30s. Many younger women appear to be delaying childbearing, although older women who are more financially secure and facing limited fertility horizons are not.

Hispanic women in their 20s experienced the largest fertility rate decline between 2007 and 2012 (Figure 5). Fertility rates for young women declined in other racial groups as well, but the declines were more modest. These changing patterns of fertility have implications for the diversity of young children. Because of the precipitous decline in Hispanic fertility rates, Hispanic births declined between 2007 and 2012 despite an increase of nearly 16 percent in the number of Hispanic women of prime childbearing age. Non-Hispanic white and black births also dropped because of lower fertility rates and fewer women of childbearing age.

\section{Hispanic Population Gains Stimulate Population Growth of Minority Youth}

From a demographic standpoint, Hispanics are driving rapid increases in racial diversity among America's children. In fact, 


\section{FIGURE 5. FERTILITY RATE FOR WOMEN AGE 20-29 AND 30-39 BY RACE/ HISPANIC ORIGIN, 2007 AND 2012}

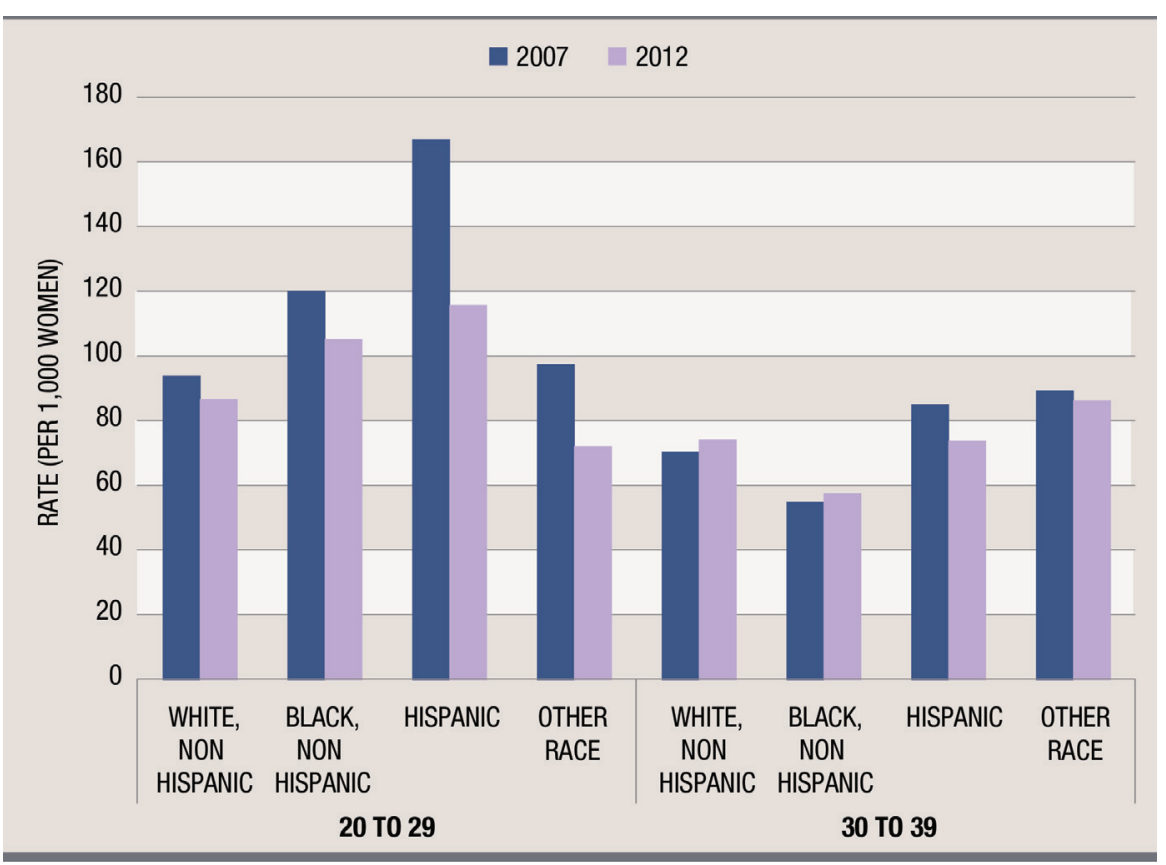

Source: NCHS 2007 and 2012

75 percent of the growth in the minority child population between 2000 and 2012 was attributable to Hispanic births. The initial reason for recent population gains in Hispanic children has been immigration. Between 2000 and 2012, 5.6 million Hispanics immigrated to the United States, supplementing the 7.7 million who arrived during the 1990s. Most new immigrants are young adults of prime childbearing age. This influx, coupled with the large Hispanic population of childbearing age already in the United States, produced the surge in Hispanic births.

Indeed, three-fourths of the entire Hispanic population gain between July of 2011 and July of 2012 came from natural increasethe difference between births and deaths-rather than immigration. Furthermore, this percentage is increasing. Hispanics are also younger, which influences mortality as well as fertility. In 2012, there were 6.7 births for every Hispanic death; in contrast, the ratio was 1.0 and 2.4 births for every death among non-Hispanic whites and blacks, respectively.

Three-fourths of the entire Hispanic population gain between July of 2011 and July of 2012 came from natural increase-the difference between births and deathsrather than immigration.

This high birth-to-death ratio is responsible for increasing numbers and shares of Hispanics. Indeed, Hispanics accounted for 54.5 percent of the U.S. population gain between 2000 and 2012, although they represented only 16.9 percent of the population.

An increasing share of minority children are U.S. born rather than foreign born. Minority childrenparticularly Hispanics and Asians-are the new second generation (that is, native-born of foreign-born parents). U.S.-born children accounted for at least 95 percent of all children under the age of 5 for each of the major minority groups considered here in 2012. A substantial share of nativeborn minorities was born to foreign-born parents, some of whom are undocumented immigrants, raising new policy concerns about so-called anchor babies-children who are U.S. citizens but whose parents are undocumentedalthough the empirical evidence is limited. In 2008, only 39 percent of 0 - to 4-year-old Hispanic children had two native-born parents. At that time, an additional 17 percent had one native-born parent and the remaining 44 percent had two foreign-born parents. In 2008, the Pew Research Center estimated that 40 percent of native-born Hispanics under age 18 with at least one foreign-born parent had at least one unauthorized parent. However, the oldest U.S.-born children of the Hispanic immigrant streams arriving in large numbers in the 1980s and 1990s are now having children of their own. As a result, the percentage of Hispanic children with U.S.-born parents is expected to grow in the near future. In fact, the Pew Research Center estimates that the share of Hispanic youth who are the children of immigrants will soon peak. ${ }^{3}$ 


\section{Minority Youth}

\section{Populations Increasing}

Fastest Outside Large Urban Cores

The conventional wisdom is that increasing diversity is primarily a big-city phenomenon. However, the evidence suggests otherwise; the new growth of minority children is spatially broad-based. In fact, the largest absolute and percentage gains are outside the urban core counties of metropolitan areas with more than 1 million residents (Figure 6). Indeed, the suburban and smaller metropolitan counties, in which minority population gains are now most heavily concentrated, are home to 45.1 million (55 percent) of the nation's 82.5 million young people. A significant majority are non-Hispanic white (59 percent), despite a decline of
2.6 million (-9.1 percent) since 2000. In contrast, minority children and youth populations, regardless of racial and ethnic background, grew rapidly outside the largest metropolitan cores. The number of Hispanic youth, for example, has swelled by 3.4 million ( 58.7 percent) since 2000; this is the largest gain of any minority population in any area during this period.

In large urban cores, where minority populations have traditionally clustered, 66 percent of the 24.5 million children and youth are minorities. The population of minority children has grown by more than 1.8 million in these areas since 2000 . Population declines among blacks and whites have been offset by this large Hispanic population gain.

Minority children constitute a considerably smaller share of all nonmetropolitan children (29 percent) than

\section{FIGURE 6. POPULATION CHANGE FOR THOSE UNDER AGE 20 BY RACE/HISPANIC ORIGIN AND METROPOLITAN STATUS, FROM 2000 TO 2012}

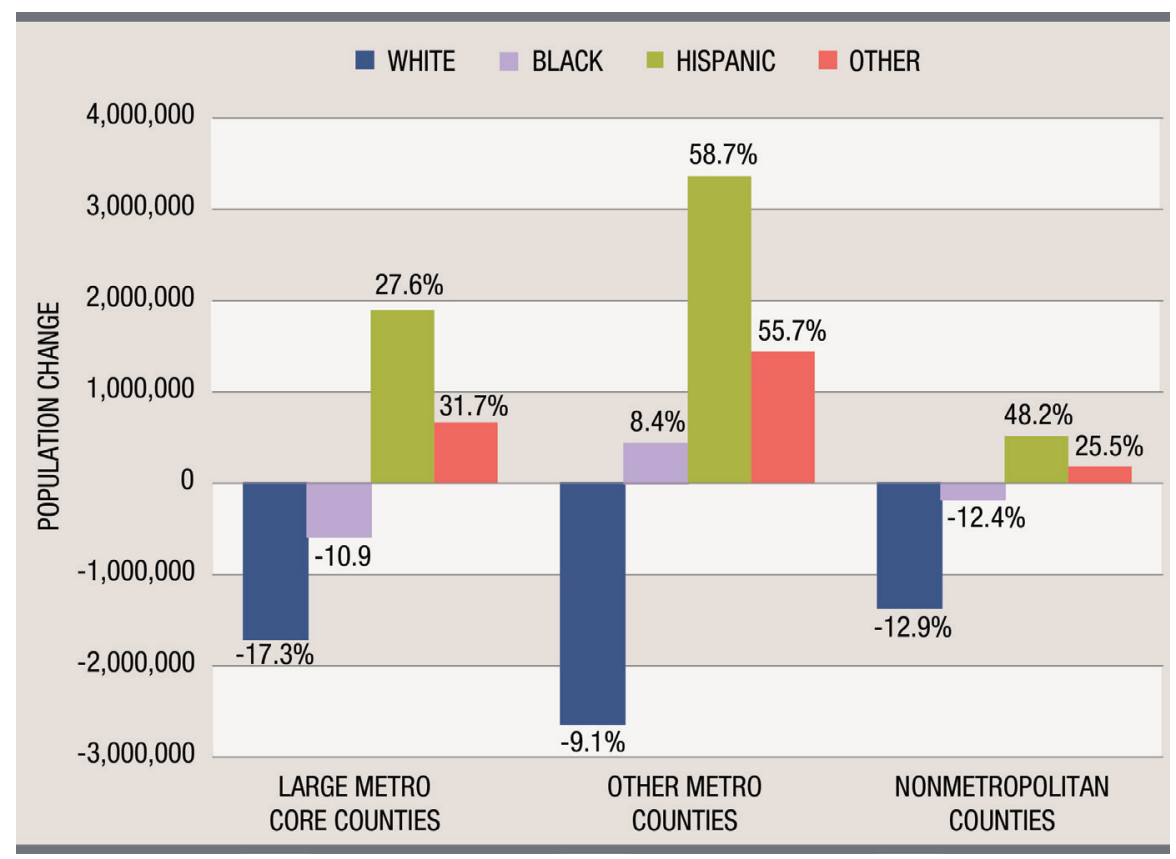

Source: U.S. Decennial Census 2000; U.S. Census Population Estimates (2012) of metropolitan children (51 percent). In fact, rural areas had 837,000 fewer young people in 2012 than in 2000 , because there were 1.4 million (-12.9 percent) fewer non-Hispanic white youths. Declines in the young black population were nearly proportionally equal to decline in the young white population (-12.4 percent). The large population gains in Hispanic young people (48.2 percent) were insufficient to fully offset losses of blacks and non-Hispanic whites. As a result, the rural youth population declined by 6.1 percent after 2000 .

National trends mask substantial geographic variation in America's racial and ethnic makeup. The majority of the young population in 606 counties is now composed of minorities (that is, majority-minority counties), and another 306 counties are near majority-minority status, with between 40 and 50 percent minority youth populations (Figure 7). Young people clearly are a harbinger of future racial change and diversity in America, particularly as deaths among the older, primarily white population are disproportionately replaced by minority births. In 2012, substantially more counties had majority-minority youth populations than counties that had majority-minority populations spanning all age groups (606 versus 353).

Most majority-minority counties are concentrated in traditional minority settlement areas. For example, large minority youth population clusters, particularly in the Southwest and the Mississippi Delta, are a continuing legacy of America's past (for example, slavery in the South). New concentrations of majority-minority counties in the Carolinas and Georgia, in the Pacific Northwest, and in Colorado 


\section{FIGURE 7. CONCENTRATION OF MINORITY POPULATION UNDER AGE 20, 2012}

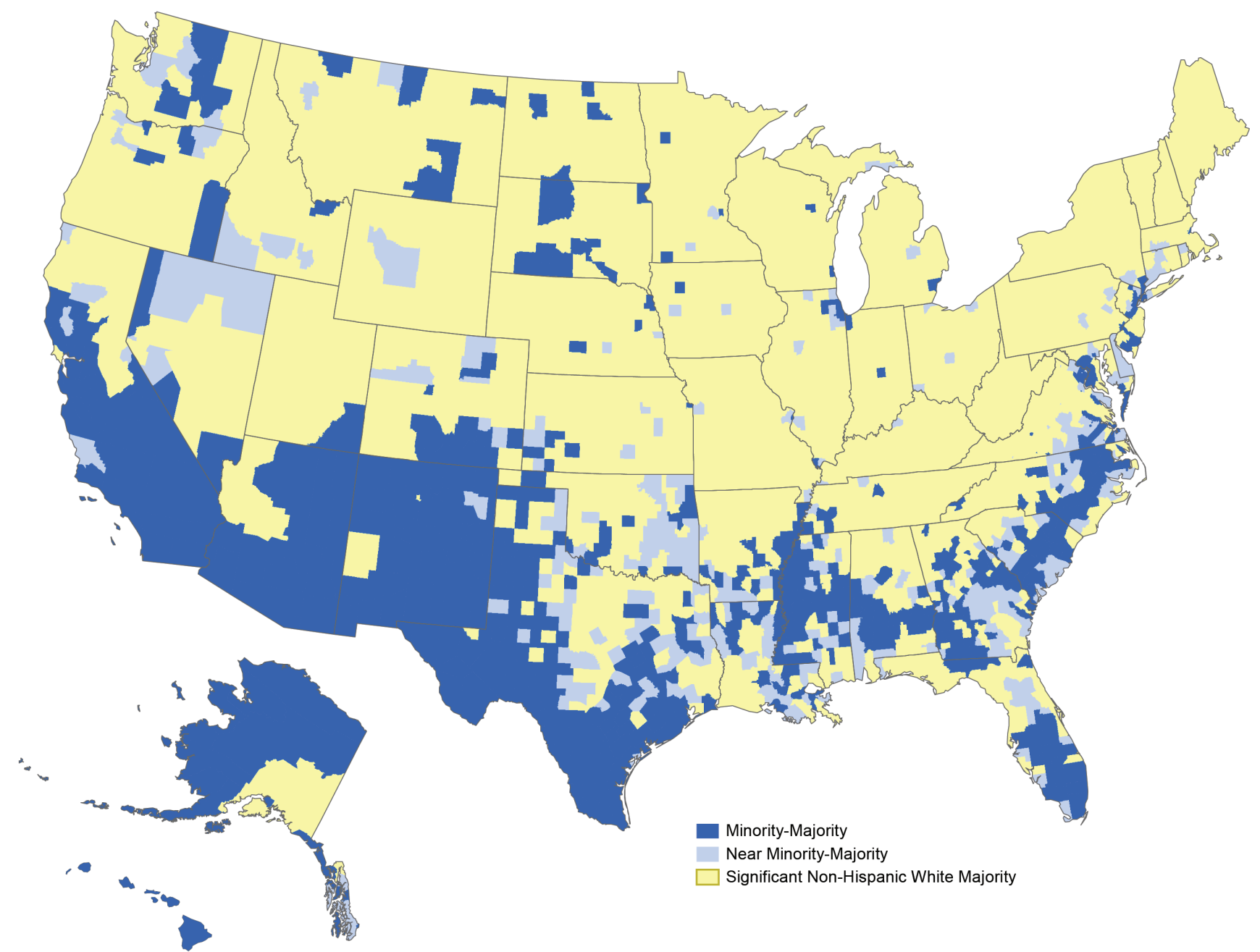

Source: U.S. Census Population Estimates (2012)

also reflect the geographic spread of minority children and youth, particularly Hispanics.

Even in regions in which minorities are not approaching majority status, diversity is rapidly accelerating. To illustrate this trend, we calculated a diversity index, which indicates the probability that two randomly selected young people in a county will be of a different race or ethnicity. For example, a diversity index of 0.50 means that a young person residing in that county has approximately a 50 percent chance of random exposure to a young county resident who is of a different race or ethnicity.

Nearly all of the Southeast and Southwest have at least moderate levels of diversity, and that diversity extends to the sprawling metropolitan regions of the Midwest and East (Figure 8). However, large areas of the country reveal comparatively limited racial and ethnic diversity, including the vast agriculture heartland in the upper Midwest with the exception of scattered counties in the Great Plains (for example, Native American Reservations and new Hispanic destinations with food processing plants). Diversity is also modest in the Northeast in areas outside the coastal urban agglomeration.

The combination of specific minority groups creating or 


\section{FIGURE 8. RACIAL DIVERSITY OF POPULATION UNDER AGE 20, 2012}

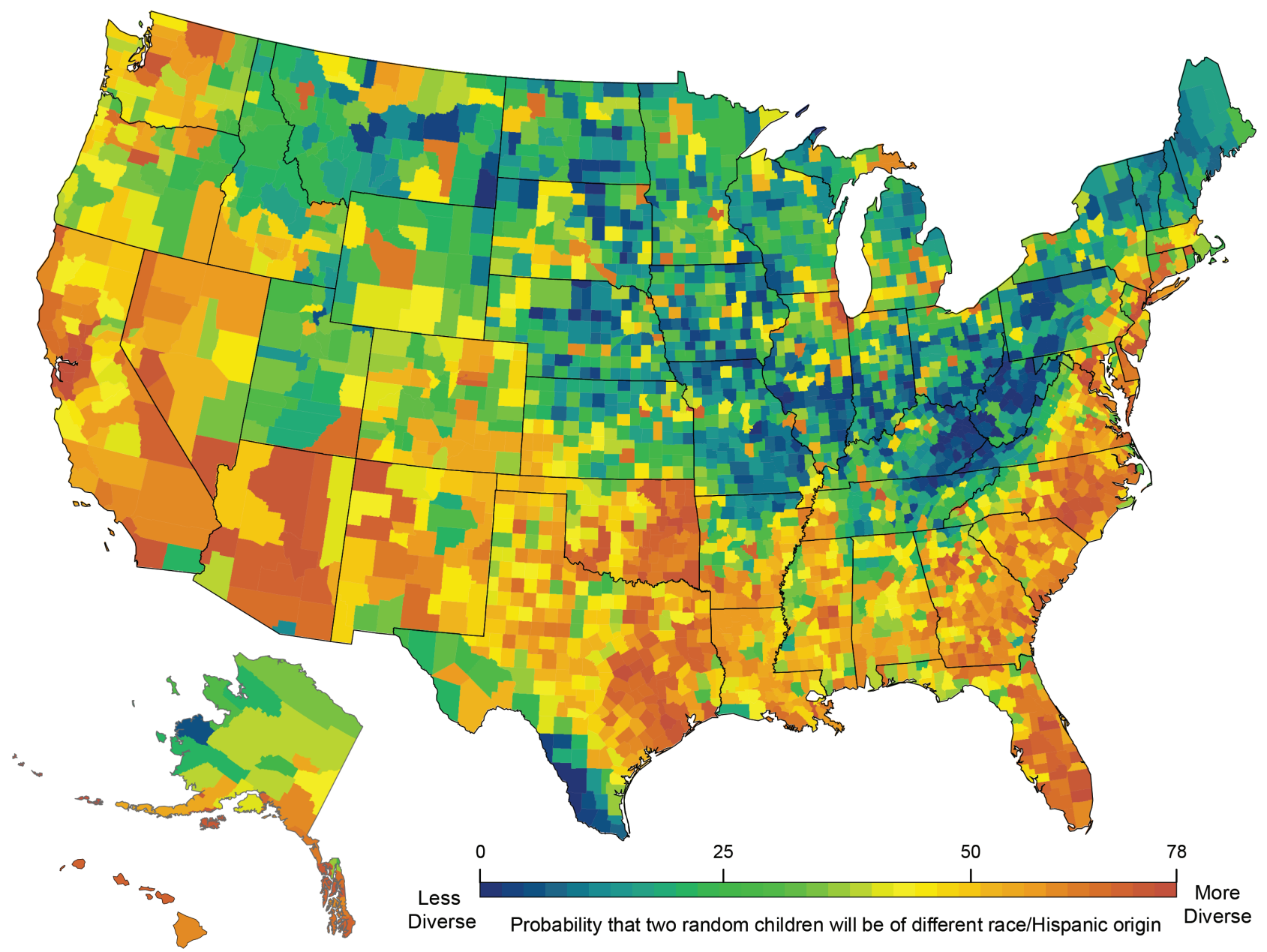

Source: U.S. Census Population Estimates (2012)

limiting diversity varies by place (Figure 9). Here, a spatial representation of minority youth concentrations reflects the number of minority groups that represented more than 10 percent of the youth population in a given county. The map reflects both the vestiges of historical minority settlement patterns and the influence of contemporary demographic trends. The large county clusters with significant black youth minorities in the South reflect historical black settlement patterns in the antebellum South. The new spatial distribution of Hispanics in the Southwest reflects historical patterns of border settlement, contemporary migration, and natural population increase. The scattered clusters of native peoples also illustrate a legacy of traditional settlement patterns and forced resettlement. However, for nearly one-half of all counties, no minority groups reached 10 percent of the population, underscoring a simple but straightforward demographic point: National data are often used to suggest the rapid spread of diversity, glossing over large disparities in the spatial distribution of minority youth.

In 2012 , only 322 counties had two youth minority groups that each represented 10 percent of the overall county population. Nevertheless, the effect of 


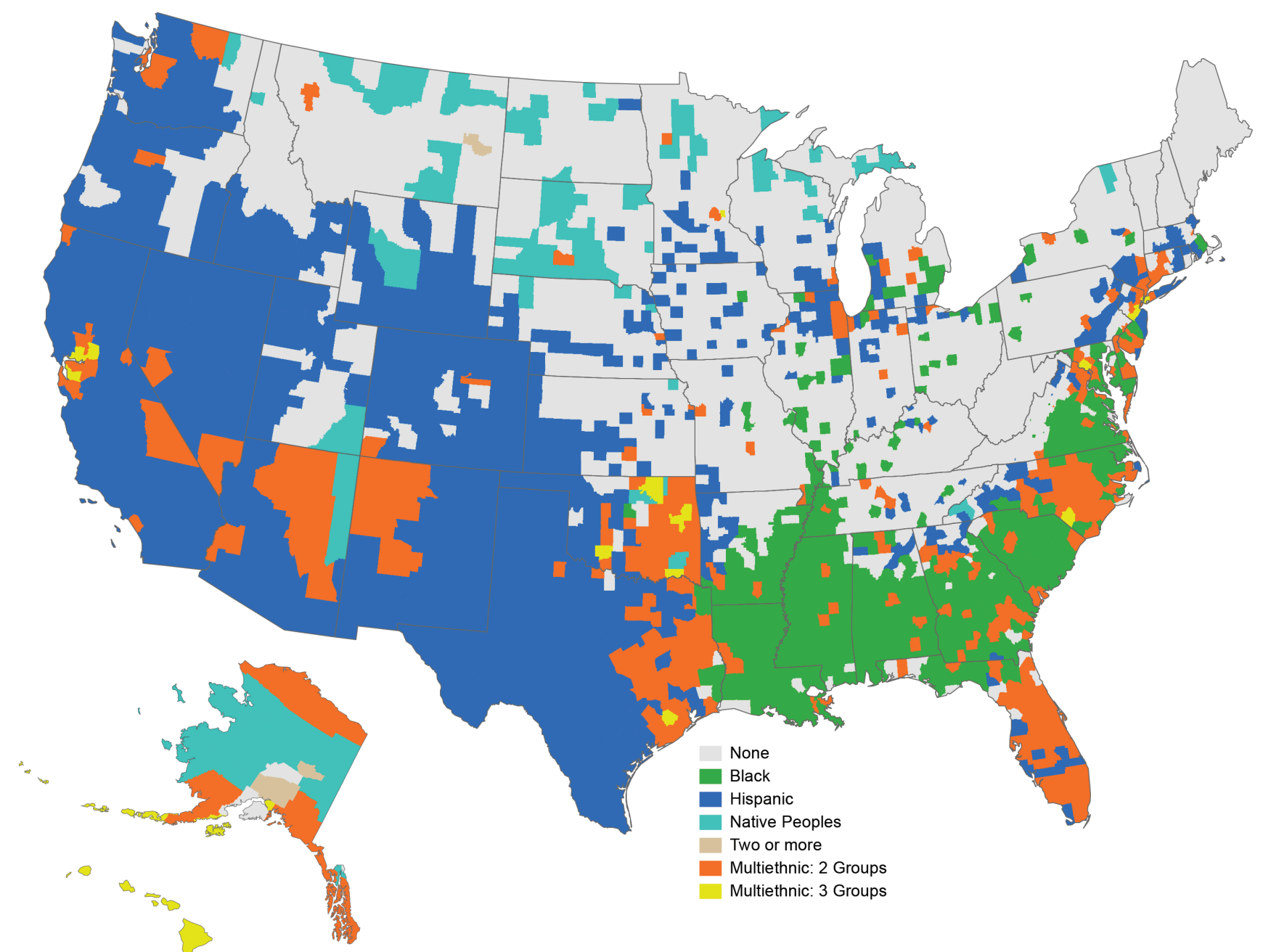

Source: U.S. Census Population Estimates (2012)

contemporary trends was most evident in these counties. In North Carolina, where blacks were once the only visible minority population, diversity is now redefined by the recent arrival of Hispanics. ${ }^{4}$ The scattered Hispanic population clusters in traditional agricultural areas of the Great Plains and Corn Belt also reflect contemporary demographic trends. Here the demand for agricultural-related labor, such as meatpacking and irrigated agriculture, exceeded the local labor force depleted by decades of white out-migration and low fertility. The influx of young Hispanic families has important demographic consequences as well. Minority inmigration may break the cycle of natural population decrease caused by persistent out-migration and low fertility of natives.

In the Washington, DC metropolitan area, the historical concentration of blacks, combined with recent in-migration of Hispanics and Asians, have produced one of America's most diverse populations of children and youth. Such broadly diverse counties remain rare, however, even when our demographic lens focuses on young people. Only 24 of the 3,141 U.S. counties contained three or more identifiable minority youth populations (of 10 percent or more) in 2012. 


\section{Conclusion}

Issues of race and racial inclusion continue to occupy much of public discourse in America. The influx of nearly 1 million immigrants annually-primarily from Latin America and Asia-has further fueled debates about multiculturalism and social, economic, and cultural fragmentation (for example, English language use, increasing multiracial intermarriage, increasing multiracial populations, and political and economic power). The Census Bureau's recent projection of a majority-minority U.S. population by the middle of the century has sometimes been the source of alarmist rhetoric about the role of immigration in America's future and the nation's essential character. We argue here that racial and ethnic multiculturalism are also driven by recent fertility patterns in the United States, revealed in the rapidly increasing racial and ethnic diversity among America's children and youth.

Our research highlights the two demographic forces that have placed today's young people in the forefront of America's new racial and ethnic diversity. The first is the rapid increase in the number of minority youths, with Hispanics accounting for the vast majority of population gains since 2000. A second but less widely recognized shift is the absolute decline of non-Hispanic white young people. Together, these two trends have resulted in increasing proportions of minority children and youth. America is becoming a majority-minority society-with children leading the way.

The Great Recession and its aftermath have slowed the growth of the U.S. population. Had the recession not occurred and the fertility trends of 2007 been sustained, we estimate there would have been 1.3 million additional births between 2007 and 2012. Furthermore, if past fertility trends persisted, more than one-half of all these foregone births would likely have been minority. Key questions are as follows: Are these foregone births lost forever or simply delayed, to be made up as the economy recovers? If they are delayed births, how quickly will they come and will the rate of increase be consistent for all racial/Hispanic groups? As is evident from our previous analysis, disproportionate shares of the foregone births were to Hispanic mothers. If Hispanic women now have children who were delayed during the recession, youth diversity will accelerate quicker.

An additional question concerns the timing of the births that did not occur because of the recession.
If the "catch-up" in births occurs simultaneously with higher fertility rates typical of economic recovery and growth, the result will be a significant surge in births and larger cohorts of young children. However, although the pace and pattern of fertility change resulting from the recession has short-term implications, powerful demographic forces guarantee that America's children and youth will lead the nation's increasing diversity.

Our results also highlight the increasing racial divide along the dimensions of age and geography. Approximately 47 percent of the youth population in 2012 were minority, compared with 36 percent of the 40 - to 45 -year-olds and less than 21 percent of those 65 and older (Figure 10), raising important questions about intergenerational support for social

\section{FIGURE 10. PERCENT OF YOUNG, WORKING AGE, AND SENIOR POPULATION THAT IS NON-HISPANIC WHITE AND MINORITY, 2012, 2030, AND 2050 PROJECTIONS}

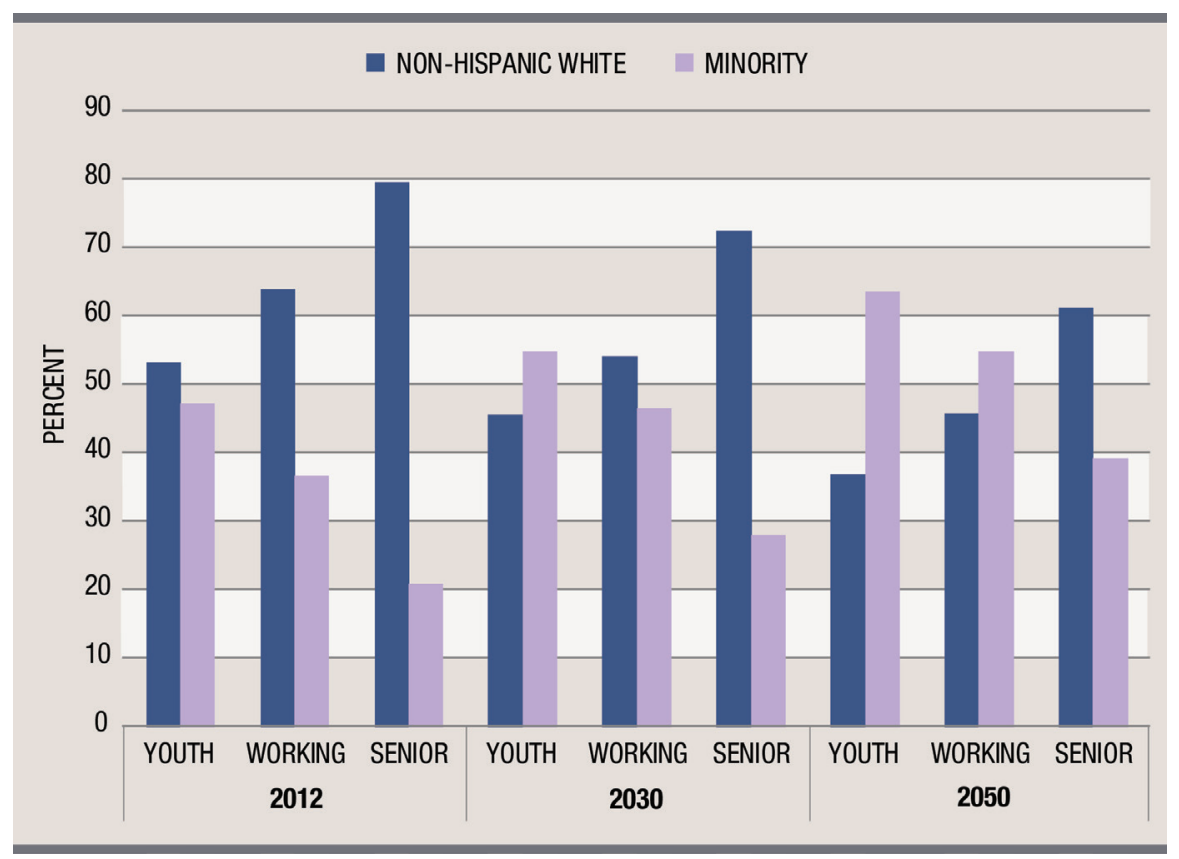

Source: U.S. Census Estimates and Projections 
programs. ${ }^{5}$ For example, will America's older, primarily white population-through the ballot box and collective self-interestsupport young people who are now much different racially and perhaps culturally from themselves and their own children? Will the older, white population vote to raise taxes to assist schools that serve young people who differ from them ethnically or racially? Some evidence suggests that the presence of large fractions of elderly residents in a jurisdiction is associated with significantly less spending per-child for education, particularly if the elderly and children are disproportionately represented across racial and ethnic groups. ${ }^{6}$ On the other hand, it is likely that increasing shares of America's seniors will have children and grandchildren who are in or result from interracial marriages, a fact that binds generations rather than separates them. Conversely, as the minority population ages and constitutes a larger proportion of the workingand voting-age population, will they be supportive of expanding entitlement programs for older adults who will still be primarily non-Hispanic white?

Our finding of greater diversity among the nation's youngest residents also offers grounds for optimism. The multiracial and multiethnic character of communities in which children are raised influence race relations and cultural boundaries, both now and in the future. Diverse communities provide better opportunities for mutual understanding and acceptance. For America's young people, increasing exposure to racial diversity will remake patterns of multiracial relations and friendship networks. Attitude surveys show that young people are much more racially tolerant than older people and that prejudice has declined as the older generation fades from the scene to be replaced by the next generation. ${ }^{7}$

America is becoming a majorityminority society-with children leading the way.

Optimism about improved relations among young people of diverse backgrounds must be tempered by spatial disparities in racial composition and diversity. The increasing racial and ethnic diversity of America's youth is no longer limited to the large multiracial urban cores or to regions where minorities historically settled. Instead, the post-2000 period ushered in a new pattern of accelerated dispersion among minority children and youth. Yet, broad geographic regions still provide few significant opportunities for daily interaction between young people with different racial and cultural backgrounds. Furthermore, evidence of increasing racial diversity among youth at the county level does not demonstrate that diversity exists across communities or neighborhoods. ${ }^{8}$ The geographic landscape of race currently suggests two Americas-an increasingly racially diverse nation versus a primarily white nation. Opportunities for racial and ethnic interaction, and opportunities for mutual understanding and acceptance, vary by place.
Our research contributes to policy discussions by highlighting the new diversity among America's youth and the changing geographic scale of the expression of this diversity. Our research also provides a window to America's future. ${ }^{9}$ As we demonstrate here, the changing racial and ethnic composition of America's youngest populations can be traced to two forces: differential changes in the numbers of women of childbearing age by race and Hispanic origin, and differential rates of fertility, particularly higher fertility among Hispanics, which is a by-product of recent immigration trends. In a policy environment usually focused on immigration, recognizing the rising importance of other demographic factors is no small achievement. With or without restrictive immigration legislation, America is becoming an increasingly diverse society though this diversity is experienced unevenly spatially. Natural population increaseparticularly fertility rates-will continue to reshape the racial and ethnic mix of the country, and this change will be reflected first among the nation's youngest residents.

\section{Methodology}

We used multiple sources of data for our analyses. The primary sources of contemporary data are the Decennial Census of 2010 and Census Bureau annual estimates of the population by age, sex, race, and Hispanic origin from April of 2010 to July of 2012, released in May of 2013. ${ }^{10}$ We also used Census Bureau estimates of births and deaths by race and Hispanic origin. We supplemented 
these sources with historical data from the 1990 and 2000 Census that has been adjusted for under enumeration by age, race, and Hispanic origin. Furthermore, respondents who classified themselves as multiracial in 2000 were allocated to racial categories to make them compatible with the 1990 census data. ${ }^{11}$ We also used birth data from the National Center for Health Statistics to examine fertility rates and trends. ${ }^{12}$

Understanding America's changing racial and ethnic composition is a challenging endeavor, partly because measurement is typically based on self-identification or self-reporting. Racial and ethnic self-identification is also highly subjective, situational, and fluid. We cannot adjudicate current debates about proper racial and ethnic classification using the secondary data at our disposal. We therefore advise a cautious approach to the evidence and recognition of the inherent subjective nature of our demographic exercise.

For most purposes, we classified the population into four groups: (1) Hispanics of any race, (2) non-Hispanic whites, (3) nonHispanic blacks, and (4) all other non-Hispanics, including those who reported two or more races. Asians were the largest racial group included in this fourth category, constituting 51 percent of those under age 19 in the category. Also included in this category are native peoples and those of two or more races. We also grouped the population into two age groups: Persons age 19 or younger were classified as "young," or the youth population. Individuals older than age 19 were grouped together into an "adult" category, which we occasionally refer to as the older population.
To examine the uneven spatial distribution of different racial and ethnic populations, we calculated summary measures of diversity. First, we estimated the number and percentage of majority-minority counties - those with at least onehalf the young population composed of minority groups-and near majority-minority countiesthose with minorities constituting between 40 and 50 percent of the population. Counties were also classified as having minority youth concentrations if more than 10 percent of the young population was from a specific minority group. Four minority groups that reached the 10 percent threshold in at least one county were as follows: blacks, Hispanics, Asians, and Native Americans. Counties that had two or more minority groups each reaching the 10 percent threshold were classified as multiethnic.

We also calculated a diversity index (DI), the so-called Simpson Index, which measures the racial and ethnic diversity of the population. ${ }^{13}$ It was calculated as follows:

$\mathrm{DI}=1-\left(\mathrm{H}^{2}+\mathrm{W}^{2}+\mathrm{B}^{2}+\mathrm{A}^{2}+\mathrm{N}^{2}\right.$ $+\mathrm{M}^{2}$ )

where $\mathrm{H}$ is the Hispanic proportion, $\mathrm{W}$ is the non-Hispanic white proportion, $\mathrm{B}$ is the non-Hispanic black proportion, $\mathrm{A}$ is the nonHispanic Asian proportion, $\mathrm{N}$ is the non-Hispanic native peoples proportion, and $\mathrm{M}$ is the non-Hispanic multiracial proportion (that is, those constituting two or more races). The values of DI range from 0 , which indicates that a county is made up entirely of one race/ethnicity, to a maximum value of 0.83 , which means that each race/ethnicity constitutes exactly one-sixth of the population. DI has a straightforward and intuitive interpretation. It measures the probability that any two children, picked at random in a county, would be of a different race or ethnicity (for example, Hispanic or non-Hispanic).

Our analysis included all 3,143 U.S. counties. We used county equivalents in the New England states, and we classified counties as metro or nonmetro using the 2003 definition created by the Office of Management and Budget. Metro areas included counties containing an urban core (or central city) population of 50,000 or more along with adjacent counties that are highly integrated with the core county, as measured by commuting patterns. There are 1,090 metro counties in the United States. We classified the remaining 2,053 counties as nonmetro. For ease of exposition, we used the terms metro and urban (and nonmetro and rural) interchangeably. We identified large metro core counties as those counties containing the central city of metropolitan areas of 1 million people or more, and we considered them separately from all other metropolitan counties. This was an important distinction, because metro counties with large urban cores historically have had large concentrations of minorities. 


\section{End notes}

1. Persons age 19 or younger were classified as "young," or the youth population. Individuals older than age 19 were grouped together into an "adult" category, which we occasionally refer to as the older population.

2. Anthony Daniel Perez and Charles Hirschman, "The Changing Racial and Ethnic Composition of the U.S. Population: Emerging American Identities," Population and Development Review, vol. 35 (2009): 1-51; D. Robert Putnam, "E Pluribus Unum: Diversity and Community in the Twenty-First Century," Scandinavian Journal of Political Studies, vol. 30 (2007): 137-174.

3. Richard Fry and Jeffrey S. Passel, "Latino Children: A Majority Are U.S.-Born Offspring of Immigrants?" (Washington, DC: Pew Hispanic Center, 2009).

4. John D. Kasarda and James H. Johnson Jr., "The Economic Impact of the Hispanic Population on the State of North Carolina," (Chapel Hill, NC: Frank Hawkins Kenan Institute of Private Enterprise, University of North Carolina at Chapel Hill, 2006).

5. Samuel H. Preston, "Children and the Elderly: Divergent Paths for America's Dependents," Demography, vol. 21 (1984): 435-457.

6. James Poterba, "Demographic Structure and the Political Economy of Public Education," Journal of Policy Analysis and Management, vol. 16 (1997): 48-66; Putnam, "E Pluribus Unum."

7. Glenn Firebaugh and Kenneth E. Davis, "Trends in Anti-Black Prejudice, 1972-1984: Region and Cohort Effects," American Journal of Sociology, vol. 94 (1988): 151-172; Kara Joyner and Grace Kao, "School Racial Composition and Adolescent Racial Homophily," Social Science Quarterly, vol. 81 (2000): 810-826; Daniel T. Lichter and Warren Brown, "Race, Immigration, and the Future of Marriage," Marriage and
Families: Complexities and Perspectives, edited by H. E. Peters and C. M. K. Dush (New York: Columbia University Press, 2009), 365-382; Putnam, "E Pluribus Unum."

8. It is unclear whether diversity and residential integration are increasing within counties (that is, across neighborhoods or cities and suburbs). Perhaps minority populations in some counties are increasing in tandem with a new kind of racial balkanization at the subcounty level. See Daniel T. Lichter et al., "Residential Segregation in New Hispanic Destinations: Cities, Suburbs, and Rural Communities Compared," Social Science Research, vol. 39 (2010): 215-230.

9. Daniel T. Lichter, "Fragmentation or Integration? Race and the American Future," Demography, vol. 50 (2013): 359-391.

10. U.S. Census Bureau, Annual Population Estimates by Age, Sex, Race, and Hispanic Origin and Estimated Components of Population Change by Race and Hispanic Origin (Washington, DC: U.S. Census Bureau, 2013), available at www.census.gov/popest/data/ national/asrh/2012/index.html.

11. Paul R. Voss et al., "County-Specific Net Migration by Five-Year Age Groups, Hispanic Origin, Race, and Sex, 1990-2000." Working paper no. CDE 2004-24 (Madison, WI: Center for Demographic and Ecology, University of Wisconsin-Madison, 2004). Dataset available at http:/dx.doi.org/10-3886/ ICPSR04171; Kenneth M. Johnson et al., "Temporal and Spatial Variation in Age-Specific Net Migration in the United States," Demography, vol. 42, no. 4 (2005): 791-812.

12. The Census Bureau and the National Center for Health Statistics (NCHS) use different methods to classify children who are born to parents who are not of the same racial/Hispanic origin group, causing inconsistencies in the allocation of births to racial and Hispanic origin categories. The Census Bureau allows births to be categorized as members of two or more racial groups based on the race of the mother and father. Conversely, the NCHS classifies babies by only one racial group and their placement is based solely on the race of the child's mother, who may be reported in only one racial category. Thus, a baby born of a white mother and a black father would be classified as of two races in the Census Bureau classification of births, but as white in tabulations of the NCHS. As the proportion of multiracial births has increased, differences between the Census Bureau's classification of births and that of NCHS have increased. In this report, we use Census Bureau birth data except when we discuss fertility rates. These rates are based on NCHS data, as reflected in the source citation for the relevant figures.

13. Philip Meyer and Shawn McIntosh, "The USA Today Index of Ethnic Diversity," International Journal of Public Opinion Research, no. 4 (1992): 51-58. 


\section{About the Authors}

Kenneth M. Johnson is senior demographer at the Carsey Institute and professor of sociology at the University of New Hampshire (ken.johnson@unh.edu).

Andrew Schaefer is a doctoral candidate in sociology at the University of New Hampshire and a research assistant at the Carsey Institute (apq62@wildcats.unh.edu).

Daniel T. Lichter is director of the Cornell Population Center and Ferris Family professor in policy analysis and management at Cornell University (DTL28@ cornell.edu).

Luke T. Rogers is a doctoral candidate in sociology at the University of New Hampshire and a research assistant at the Carsey Institute (1tp5@wildcats.unh.edu).

\section{A cknowledgements}

This brief updates and expands prior research by Johnson and Lichter including their 2010 article titled, "Growing Diversity Among America’s Children and Youth: Spatial and Temporal Dimensions," which appeared in Population and Development Review 34(2): 327-346 (March 2010) and a prior Carsey brief titled,

"The Changing Faces of America's Children and Youth" 15: 1-8 (April 2010). This research was funded by grants from the Annie E. Casey Foundation, the W. K. Kellogg Foundation, the New Hampshire Agricultural Experiment Station, and an anonymous donor. Barbara Cook of the Carsey Institute produced the maps included in the report.

\section{University of Ni New Hampshire CARSEY}

Building knowledge for families and communities

The Carsey Institute conducts policy research on vulnerable children, youth, and families and on sustainable community development. We give policy makers and practitioners timely, independent resources to effect change in their communities.

This work was supported by the Annie E. Casey Foundation, the W. K. Kellogg Foundation, The New Hampshire Agricultural Experiment Station, and an anonymous donor.

Huddleston Hall

73 Main Street

Durham, NH 03824

(603) 862-2821

TTY USERS: DIAL 7-1-1 OR 1-800-735-2964 (RELAY N.H.)

www.carseyinstitute.unh.edu 